\title{
GRG Profiles: John M. Carethers
}

\author{
John M. Carethers ${ }^{1}$
}

Published online: 5 February 2016

(c) Springer Science+Business Media New York 2016

I was born the fourth son and the tenth of 12 children. My parents pushed education as the way for their children to get ahead in life. They both had a college education. My father graduated in 1948 with a mechanical engineering degree after a medical deferment during World War II, and my mother was a secretary for her father's real estate company before marriage and was our constant in the home while my dad worked for the City of Detroit. My parents raised us with good morals and strived to provide individual needs for each child's personality and traits. I grew up in Detroit, was educated in elementary school by Catholic nuns and lay teachers, and went to the city's public magnet high school, Cass Tech. Growing up in a large family was the only norm I knew. We ate dinner as a family, attended church weekly, fought with each other, encouraged each other, and competed with each other. At least one of us seemed to make it to the emergency room at least once a year. To this day, all of my siblings get along. Despite a tight budget, the oldest 11 children attained more than 17 college degrees from two universities located in Detroit, with all costs for education borne through scholarships, grants, and loans. My youngest brother and my parent's 12th child has trisomy 21, and his Down's syndrome had an influence on the career choices of some of my family members. My own choice to pursue medicine as a career stemmed from an exploration of the Encyclopedia Britannica, with its anatomy overlays that mesmerized me.

John M. Carethers

jcarethe@umich.edu

1 Division of Gastroenterology, Department of Internal Medicine, University of Michigan, 3101 Taubman Center, 1500 East Medical Center Drive, Ann Arbor, MI 48109-5368, USA
Fate has a way of happening. My eventual pursuit of medicine ultimately led to meeting my wife during fellowship and raising four beautiful children. To this day, I try to instill a push for education in my own children, along with many interested kids with whom I come in contact.

\section{Education}

After graduating from Cass Tech with nearly 1000 senior classmates, I attended Wayne State University in Detroit, a large urban university with $\sim 30,000$ students. I majored in molecular biology and biophysics and graduated with a Bachelor's degree in biological sciences with a minor in chemistry. During my undergraduate years, my plan A was to get to medical school, and my plan B (if plan A failed) was to pursue a second Bachelor's degree in chemical engineering. Plan A worked out fine. I applied to six medical schools but only took the interviews at the Michigan schools. I was accepted to Wayne State University School of Medicine, the University of Michigan Medical School, and Michigan State's College of Medicine. After some trepidation and soul searching, plus taking into account financial considerations, I chose to enroll at Wayne State.

I invested myself in learning during my 4 years in medical school. My study habits became fixed rituals. I wanted to learn as much as I could, and I performed well, with honors in all 4 years of medical school, was elected to Alpha Omega Alpha, and finished at the top of my medical school graduating class. I received national recognition with the Franklin C. McLean Award and the Henry J. Kaiser Family Foundation Awards from National Medical Fellowships.

When I entered medical school, I really did not have any thought of entering private practice. I had always seen 
myself as someone who was part of a large academic enterprise; however, I did not have a complete road map of how to get there. During medical school, I received several pieces of advice, including "Work in your community when you are done with medical training" and "Explore research opportunities." My ideation matched the latter. In the summer after my first year of medical school, I was accepted into the laboratory of John Heggers and Martin Robson, two professors involved in thermal injury research within the field of plastic surgery. My assignment was to culture and identify bacterial infections from pig skin flaps (burns) and rabbit ears (frostbite). This work further stimulated my interest in research, particulary when my name was included on two publications from the laboratory $[1$, 2]. What a joy to see my name in print on a publication! I sought out research experiences during elective time in my third and fourth year and worked in James Sower's laboratory focused on studies using Zucker obese rats with both diabetes and hypertension, two disorders common in the US population but particularly prevalent in the AfricanAmerican population. By this time, I was hooked on focusing my career on research.

I spent nearly 4 years as a unit clerk in the operating room of Children's Hospital of Michigan during my undergraduate years that led to my initial interest in pediatric surgery, but that idea was derailed later when I came down with chicken pox in the middle of my surgery rotation. I had excellent grades and was encouraged to explore the more competitive specialties, including ophthalmology; my love for physics and optics from my undergraduate days matched this field. I also explored orthopedics and did an away rotation at the University of Washington. I entered the early match in ophthalmology but then withdrew because I felt the eye might be too limiting to me. I enjoyed the diagnostic "Sherlock Holmes" aspect of internal medicine, as well as the many research opportunities it offered. I matched at the top internal medicine residency program in the country, Massachusetts General Hospital (MGH), an achievement I was told was the first in many decades for a student from Wayne State. In subsequent years, several other Wayne State students matched at MGH after the doors had been reopened.

\section{Massachusetts General Hospital}

MGH was a different place than the urban inner city Detroit Medical Center. It had history (founded in 1811); had the Ether Dome, where the first demonstration of anesthesia occurred in the modern world; had many of the authors of Harrison's Textbook of Medicine, the most authoritative textbook of internal medicine; was a major teaching hospital for Harvard Medical School; and showcased patient cases at clinicopathologic conferences (CPCs) published in the New England Journal of Medicine, one of the highest impact medical journals in the world. MGH's purpose and attitude made it feel like the center of the medical universe. Patients came from around the world, and MGH physicians traveled the world to care for world leaders. As a new intern, I was only one of about three (out of 23 in my class) who came from a public medical school; many of my co-interns were from Harvard, Yale, Hopkins, and Penn, among others. Rounds on patients were both educational and practical experiences. Residents' diagnoses were challenged by attendings, and we were encouraged to think of possible "zebras". This approach has proved useful many times in my career. The patient cases I saw were incredible, and the experiential learning and supervisory growth were exponential over my 3 years at MGH. Medical luminaries, from the Chief of Medicine John Potts, a noted endocrinologist, to Jules Dienstag, an outstanding hepatologist and clinical researcher, to the late Morton Schwartz, probably the most encyclopedic medical mind that I have ever known, were my attendings, and I learned a great amount from them.

As I progressed into my junior residency year, I began to think of subspecialty internal medicine. My rotation on oncology intrigued me. Then, in November of my junior year, I rotated with Dr. Dienstag, and I was influenced by his thoughtfulness about patients, as well as his strong participation in clinical research, and I decided to pursue gastroenterology as a subspecialty. I spoke with Daniel Podolsky, then Chief of Gastroenterology at MGH, and let him know of my interest. I was interested in applying to true academic programs with NIH-funded investigators and T32 training grants that supported young developing researchers. I focused on programs at which I could develop as a gastrointestinal oncologist. I met several incredible young faculty who have become leaders over time. I rounded on patients with Anil Rustgi (now Chief of Gastroenterology at Penn), met Juanita Merchant (now a Professor at Michigan), and also met Timothy Wang (now Chief of Gastroenterology at Columbia). I will be forever grateful to the environment that MGH provided in stimulating me and creating points of contact for the future.

\section{University of Michigan}

I matched at the University of Michigan, and several influences led to that match. First, Tadataka Yamada, the Chair of Internal Medicine and former Gastroenterology Division Chief, sent me a personal letter expressing his and the division's interest in me. Second, Michigan had an outstanding gastrointestinal cancer researcher, Andrew Feinberg, who was suggested to me as a mentor. Third, I 
would be near several of my siblings in the Detroit area. In addition, while $\mathrm{MGH}$ was the place to be for internal medicine training, Michigan was the place to be for gastroenterology training under Yamada's and Dr. Chung Owyang's leadership. Clinically challenging and stimulating cases, innovative approaches to care, and multiple luminaries in the gastroenterology world were at Michigan. Michael Lucey was one of the top researchers in alcoholic liver disease as well as liver transplantation; the late Timothy Nostrant was a diagnostician extraordinaire; and Grace Elta and Jeffrey Barnett likewise were model clinicians. Several young faculty were being developed, including Peter Traber, Gary Wu, William Chey, and John Wiley. Still other faculty were nationally known in their areas, including Paul Watkins, Rebecca Van Dyke, Keith Henley, George Brewer, and William Dobbins. Still others were being recruited to Michigan, including Anna Lok and Grace Su. Collegiality was the norm, and being academic was expected. I published my first case reports as a result of these great exposures [3, 4] and began to explore how my research training should be structured. After discussion with Dr. Feinberg, I talked with another faculty member in gastroenterology, C. Richard (Rick) Boland, who worked on glycoproteins and lectins closely with Irwin Goldstein, a noted glycobiologist in the medical school. Rick was retooling his laboratory toward genetics with a sabbatical through Dr. Feinberg's laboratory, and Dr. Feinberg felt he might be a good mentor for me. This was prescient, as Rick turned out to be a great mentor for me, and Dr. Feinberg soon left Michigan for Johns Hopkins. I was not formally trained in research, and on the recommendation of Chung Owyang, I participated in a 9-week postdoctoral research training program that primed novice researchers before entering the laboratory.

Rick Boland's laboratory was the right fit for me to start my research career. Rick was a successful physician-scientist working in the area of gastrointestinal oncology and had been trained by Young Kim at the University of California, San Francisco. Rick had a personal passion for studying colorectal cancer because several of his own family members had been afflicted [5]. He was an excellent writer, patient and encouraging, honest and trustworthy, and internationally known. He proved to be a great role model not only as a physician-scientist, but also as a leader and, for me in particular, as a mentor and husband. I was extremely fortunate to have found such a fine mentor. Rick went on to become the President of the American Gastroenterological Association (AGA) [5] and received the William Beaumont Prize from the AGA for his lifelong work in colorectal cancer.

Rick set me up with a "major" and a "minor" project. My major project dealt with a specific lectin that recognized uncovered glycoproteins on colon cancer cells as a way of triggering programmed cell death, but I never published a paper in that area. However, the minor project blossomed. On a sabbatical, Rick had studied genetic markers called DNA microsatellites, which could be used to identify the pathway of microsatellite instability, a marker for deficient DNA mismatch repair. My project was to assess the effect of alkylating agents on the DNA mismatch repair system. The initial work was featured as part of a publication led by Rick's postdoctoral student Minoru Koi [6] and has now been cited over 500 times in the literature. A deeper dive into what happens with the cell cycle when DNA mismatch repair responds to altered nucleotides resulted in my first real publication, a firstauthored paper in the Journal of Clinical Investigation [7]. I felt that I was on my way to what I wanted to do.

Going to the University of Michigan for my fellowship not only opened doors for outstanding clinical training and finding an ideal research mentor, but also led me to my future wife. We met within 2 weeks of my arrival at Michigan, and we married just 2 weeks before I completed my fellowship. In academic medicine, opportunities come to those who are doing well. By the end of my fellowship, Rick had accepted the position of Chief of Gastroenterology at the University of California, San Diego (UCSD) to replace the late Jon Isenberg, and after some soul searching, as well as convincing my new bride, I accepted Rick's offer to join him in San Diego. I was making progress in the laboratory under Rick's guidance and did not want to have to find a new mentor. I ultimately spent 5 years in Rick's laboratory.

\section{University of California, San Diego}

The initial 20 months after moving to UCSD were a whirlwind, filled with family tragedy as well as success. Within 3 months of my joining the faculty as a new recruit, my mother had a massive stroke and died 2 months later. Within another year, my father was diagnosed with lung cancer and died a few short months afterward. My new wife became pregnant and had our first child, and we moved from an apartment to our first house. The Hunter Group had just consulted for UCSD Healthcare and recommended large financial changes and layoffs as a result of poor financial performance. I had just published the Journal of Clinical Investigation paper [7], obtained a National Institutes of Health (NIH) K08 mentored-scientist award, and applied a third time for a Robert Wood Johnson Harold Amos Award; the third time was the charm. The K08 and Harold Amos Award provided resources for me to commence my research career. The Harold Amos Award in particular opened up to me a new national community of physician-scholars. 
Rick Boland continued to be a great mentor. As I progressed, I had the idea of evaluating the genetics of hamartomatous polyps. Joel Lavine, then the pediatric gastroenterology division chief, followed a family with the Bannayan-Riley-Ruvalcaba syndrome. I put one of my first postdocs on the study, a talented surgeon named Andrew Zigman, who mapped the chromosomal location of the genetic mutation of this rare syndrome [8]. Unfortunately for our laboratory, another laboratory showed a few months earlier that the affected gene was the phosphatase and tensin homolog (PTEN) gene. The paper by Zigman et al. [8] was my first senior-authored publication. Understanding familial and sporadic hamartomatous polyps was the theme of my first independent NIH R01 grant that launched my independent career.

With our Journal of Clinical Investigation paper [7], we realized that DNA mismatch repair could recognize alternative nucleotides via alkylation damage to DNA. However, standard treatment of patients with colorectal cancer was not with alkylating agents, but with 5-fluorouracil (5FU). Rick urged me to challenge the conventional thinking, and this line of investigation led to several manuscripts over 15-20 years that ultimately became the basis of my election to the American Society for Clinical Investigation (ASCI), the Association of American Physicians (AAP), and the National Academy of Medicine (NAM, formerly known as the Institute of Medicine). My laboratory discovered that DNA mismatch repair can in fact recognize 5-FU that is incorporated into DNA [9]. We later showed that this had an effect on patient survival from colorectal cancer, as patients with a defective DNA mismatch repair system did not show a survival benefit with adjuvant 5-FU treatment [10]. We worked out the mechanism, showing that individual complexes from DNA mismatch repair had specific binding affinities for 5-FU incorporated into DNA $[11,12]$ and that isolating the DNA component of 5-FU (from the RNA component) proved that DNA mismatch repair could trigger cell death once it recognizes 5-FU [13]. Talented postdocs Akihiro Tajima, Moriya Iwaizumi, and Yasushi Hamaya [14] were key in figuring out this important process. The approach to patients with defective DNA mismatch repair tumors has been modified clinically because of the contribution of our research. Collaboration with Richard Kolodner, a yeast geneticist who cloned the first human DNA mismatch repair gene, was a wonderful plus at the time.

Another key area of investigation for my laboratory stemmed from the finding that the germline of some patients with familial hamartomatous syndromes showed defects in the transforming growth factor $\beta$ (TGF $\beta$ ) family, including activin and bone morphogenetic protein (BMP) members. We surmised that if TGF $\beta$ was inactivated in these colorectal cancer prone syndromes, they might be involved in sporadic colorectal cancer as well. Additionally, defective DNA mismatch repair was associated with inactivation of TGFB receptor II by frameshift mutation of a coding exon in $85 \%$ of these types of cancers. Barbara Jung, a talented physician-scientist in the laboratory at the time and currently the Gastroenterology Division Chief at the University of Illinois, Chicago, demonstrated the importance of the activin type 2 receptor, ACVR2, in colorectal cancer, both clinically and mechanistically [15, 16]. Stayce Beck, who received her $\mathrm{PhD}$ in my laboratory, was the first to show the importance of BMP in sporadic colorectal cancer behavior [17, 18]. Other talented postdocs working in this area were Sherry Huang, who focused on TGF $\beta$ in familial hamartomatous syndromes, and Jimmy Chow, who studied TGF $\beta$ signaling in pancreatic cancer.

We also wanted to be able to measure the frameshift mutation rates with defective DNA mismatch repair, something that had not been done in human cells. Heekyung Chung diligently worked out models with which to do just that and helped our understanding of how DNA can frameshift mutate in real time [19-21]. Overall, our laboratory work was generating nice discoveries regarding the function and dysfunction of DNA mismatch repair. A review co-authored with Bill Grady that expounds on the genetic instability within colorectal cancer has now garnered over 400 citations [22].

All four of our children were born in San Diego. At the same time, I progressed as a leader at UCSD. Rick Boland asked me to run and reorganize the gastroenterology fellowship as fellowship director, which I did for 7 years. Later, Rick, along with Roger Sprague, the Chief of Medicine at the San Diego Veterans Administration Medical Center, asked me to take over as the Gastroenterology Section Chief. When Rick left UCSD for Baylor University Medical Center in Dallas, I served on the search committee for the new division chief, but after some convincing by my chair at the time, Kenneth Kaushansky (along with the Dean, Edward Holmes), I recused myself from the committee, became a candidate, and was ultimately chosen as Chief of the Division. As Chief, I was able to double the size of the division faculty to $\sim 50$ members, double our clinical revenue, and more than double our NIH grant portfolio. I became the director of the division's T32 grant, obtained UCSD's first-ever NIH-funded Gastroenterology Center grant, and helped the institution and Comprehensive Cancer Center obtain an NIH U54 grant that created a partnership between UCSD and San Diego State University in the area of cancer disparities. I greatly participated in medical student and housestaff teaching, was active clinically on both the internal medicine and gastroenterology services, and recruited outstanding young faculty from inside and outside UCSD. I participated in the creation of 
the Preuss School, a 6th through 12th grade school on the campus of UCSD that provides opportunity to economically disadvantaged students for college eligibility. My nearly 15 years at UCSD was a period of growth for me personally and, along with the changes that I experienced there, prepared me for the next stage of my career.

\section{University of Michigan: The Return}

I sought a lot of advice from many current and former Chairs of Medicine when the opportunity came for me to consider becoming Chair of Internal Medicine at the University of Michigan. The best piece of advice was to have a great and synergistic programmatic and ideation relationship with my supervisor. Jim Woolliscroft, then the Dean of the University of Michigan Medical School, asked me to contemplate taking the position, for which I was ultimately selected. He has been a great partner and colleague. Filling the shoes of former Michigan Chairs and luminaries of modern medicine William Kelley and Tadataka Yamada initially seemed daunting. But the era was different, and the financial, clinical, and research models were markedly changed compared with the past. I was pleased that the University of Michigan remained a wonderful institution and that I could fit in and direct the largest department at the University. In the more than 6 years that I have held this position, the department has grown from 585 to 760 faculty; the department's endowments have grown from 28 professorships to 80 ; six of the 12 division chiefs have turned over after significant longevity and divisional investment; and the department is ranked number seven in the USA by U.S. News \& World Report. The department retains one of the most profound NIH grant portfolios in the country and has grown in the number of faculty who have been elected to the ASCI, AAP, and NAM. The division chiefs have been outstanding partners in the recruitment and management of fantastic faculty and have contributed immensely to the department's accomplishments. Chung Owyang in particular had been my division chief as a fellow, and here was I returning to be his immediate supervisor. The department has had many successes as well as challenges that we have addressed head on. My goal has always been to make our department the one that other departments of medicine around the country emulate. Treating everyone with respect no matter the situation and careful listening have been cornerstones of my chairmanship.

Because of the increased administrative component for my position, I limited my clinical time to one clinic a week (the Cancer Genetics Clinic) and passed on my endoscopy cases to others in the Gastroenterology Division. The Cancer Genetics Clinic evaluates a number of patients who are at high risk of cancer, and in particular hereditary colorectal cancer [23]. I decided to keep my research portfolio and have renewed and received new NIH grants since becoming chair.

In terms of research, I have been fortunate to have hired excellent cancer biologists within my laboratory to facilitate answering our research hypotheses. Minoru Koi, who was originally employed by Rick Boland (thus tying our two research generations together), and Stephanie TsengRogenski joined as faculty in my laboratory. Both have extended the laboratory's work on DNA mismatch repair, with basic and clinical implications for patients with colorectal cancer. Minoru has discovered a genetic signature that predicts the outcome of colorectal cancer patients [24], and Stephanie has discovered a unique mechanism to inactivate a portion of DNA mismatch repair that appears to occur in over $50 \%$ of colorectal cancer patients [25-27]. Carmen Zhang and Maide Raeker have also contributed greatly in organizing the laboratory and performing key experiments. Many students have come through the laboratory as well.

Another burgeoning interest of mine is the biology of cancer disparities. Little data existed when I wrote my first review on the subject as an assistant professor [28], but with the advent of our U54 grant at UCSD and a new branch at the National Cancer Institute that placed some focus on cancer disparities (plus my later acquisition of two independent NIH grants at the University of Michigan), my laboratory has been examining the unique aspects of DNA mismatch repair regulation and dysfunction among African-American colorectal cancer patients and proposed some policy shifts for colorectal cancer screening [29-32].

Overall, the University of Michigan continues to be a great place to lead a wonderful department and to conduct research. I do many of the things I expect my faculty to do: teaching, scholarship, and clinical practice. My overall role is to promote the faculty in my department in what they do. I created a new Clinical Excellence Society within the department to recognize clinical excellence, something generally not accounted for in academic promotion packages. In the meantime, I strive to maintain a national and international stature in research and participate in national committees, and write timely reviews in my area of research specialty $[33,34]$. International collaboration for the department has also grown, with an education focus in Ethiopia and a translational research focus with Peking University Health Science Center in China.

\section{Lessons Learned and the Future}

I think the future continues to be bright for physician-scientists and developing leaders, despite all the chatter about tight NIH funding. The advice I received when I started out 
in research is to continue to ask questions and explore; if you do good work, the funding will come. With this attitude, I have had continuous research funding since my fellowship days.

Specific advice that I would give young developing faculty members include:

- Identify an appropriate mentor(s) who have a track record of developing mentees, and show your mentor that you have the drive and desire to succeed. Your success is the mentor's success. The individual often becomes a lifelong mentor and has a vested interest in your development. To this day, I still seek advice from my research and career mentor, Rick Boland. Having co-mentors is fine as well.

- Take time to learn from your mentor(s). Mentorship is not a crash course. I spent 5 years in my mentor's laboratory to learn the basics of developing research approaches and hypotheses and to relearn how to write a good grant, produce a good manuscript that tells a story, and become a good mentor myself.

- Create a research focus by the time you become a junior faculty to carve out a niche for the next 5 years or longer. Answer the question, "What do you want to be known for within academic medicine in the next 5-10 years?"

- Work hard, and others will notice you. I had no experience running a fellowship program nor being a division chief or chair of a department.

- Be courteous to others at all stages of your career. In academics, faculty can move into positions at different paces. Your resident, fellow, or junior faculty colleague might become your boss one day, or you could become that individual's boss, as in the case of Chung Owyang.

- Maintain a supportive family or support structure. Academics has its ups and downs, as do life experiences, and your support structure can help with the difficult times and celebrate the good times with you.

- Carefully examine and take advantage of opportunities that others might present to you. There may be a good reason why an opportunity came to you, and you should learn from that opportunity, rather than potentially squander it.

Learning in academic medicine is lifelong, and I am still learning from mentors as well as from younger faculty with whom I come in contact. I continue to think my own future is bright within academic medicine, because I expect to contribute to our academic tripartite mission for years to come.

Acknowledgments I am supported by the United States Public Health Service (DK067287 and CA162147) and the A. Alfred Taubman Medical Research Institute of the University of Michigan. This article is dedicated to my wife Denise and our four children for their contribution to the success of my career. Their efforts and understanding have been incredible with my foray into academic medicine.

\section{References}

1. Heggers JP, Robson M, Manavalen K, et al. Experimental and clinical observations on frostbite. Ann Emerg Med. 1987;16:1056-1062.

2. Heggers JP, Phillips LG, Boertman JA, et al. The epidemiology of methicillin-resistant Staphylococcus aureus in a burn center. J Burn Care Rehabil. 1988;9:610-612.

3. Carethers JM, McDonnell WM. Images in clinical medicine. Extraintestinal manifestations of Crohn's disease. $N$ Engl J Med. 1994;330:1870.

4. Carethers JM, McDonnell WM, Owyang C, Scheiman JM. Massive secretory diarrhea and pseudo-obstruction as the initial presentation of Crohn's disease. J Clin Gastroenterol. 1996;23: $55-59$.

5. Carethers JM, Goel A. Our New AGA Institute President-C. Richard Boland, M.D. Gastroenterology. 2011;140:1675-1679.

6. Koi M, Umar A, Chauhan DP, et al. Human chromosome 3 corrects mismatch repair deficiency and microsatellite instability and reduces $N$-methyl- $N^{\prime}$-nitro- $N$-nitrosoguanidine-tolerance in colon tumor cells with homozygous $h M L H 1$ mutation. Cancer Res. 1994;54:4308-4312.

7. Carethers JM, Hawn MT, Chauhan DP, et al. Competency in mismatch repair prohibits clonal expansion of cancer cells treated with $N$-methyl- $N^{\prime}$-nitro- $N$-nitrosoguanidine. $J$ Clin Investig. 1996;98:199-206.

8. Zigman AF, Lavine JE, Jones MC, Boland CR, Carethers JM. Localization of Bannayan-Riley-Ruvalcaba syndrome gene to chromosome 10q23. Gastroenterology. 1997;113:1433-1437.

9. Carethers JM, Chauhan DP, Fink D, et al. Mismatch repair proficiency and in vitro response to 5-fluorouracil. Gastroenterology. 1999;117:123-131.

10. Carethers JM, Smith EJ, Behling CA, et al. Use of 5-fluorouracil and survival in patients with microsatellite unstable colorectal cancer. Gastroenterology. 2004;126:394-401.

11. Tajima A, Hess MT, Cabrera BL, Kolodner RD, Carethers JM. The mismatch repair complex hMutS $\alpha$ recognizes 5-fluoruracilmodified DNA: implications for chemosensitivity and resistance. Gastroenterology. 2004;127:1678-1684.

12. Tajima A, Iwaizumi M, Tseng-Rogenski S, Cabrera BL, Carethers JM. Both hMutS $\alpha$ and hMutS $\beta$ complexes participate in 5-fluoruracil cytotoxicity. PLoS One. 2011;6:e28117.

13. Iwaizumi M, Tseng-Rogenski S, Carethers JM. DNA mismatch repair proficiency executing 5-fluorouracil cytotoxicity in colorectal cancer cells. Cancer Biol Ther. 2011;12:756-764.

14. Hamaya Y, Guarinos C, Tseng-Rogenski SS, et al. Efficacy of 5-fluorouracil adjuvant therapy for patients with EMAST-positive stage II/III colorectal cancers. PLoS One. 2015;10:e0127591.

15. Jung B, Doctolero RT, Tajima A, et al. Loss of activin receptor type 2 protein expression in microsatellite unstable colon cancers. Gastroenterology. 2004;126:654-659.

16. Jung $\mathrm{BH}$, Beck SE, Cabral J, et al. Activin type 2 receptor restoration in MSI-H colon cancer suppresses growth and enhances migration with activin. Gastroenterology. 2007;132: 633-644.

17. Beck SE, Jung BH, Fiorino A, et al. Bone morphogenetic protein signaling and growth suppression in colon cancer. Am J Physiol Gastrointest Liver Physiol. 2006;291:G135-G145.

18. Jung BH, Beck SE, Carethers JM. Bone morphogenetic protein (BMP) and activin signaling in colon cancer. Curr Cancer Rep. 2008;4:71-76. 
19. Chung H, Young DJ, Lopez C, et al. Mutation rates of TGFBR2 and $A C V R 2$ coding microsatellites in human cells with defective DNA mismatch repair. PLoS One. 2008;3:e3463.

20. Chung H, Lopez CG, Young DJ, et al. Flanking sequence specificity determines coding microsatellite heteroduplex and mutation rates with defective DNA mismatch repair. Oncogene. 2010;29:2172-2180.

21. Chung H, Lopez CG, Holmstrom J, et al. Both microsatellite length and sequence context determine frameshift mutation rates in defective DNA mismatch repair. Hum Mol Genet. 2010;19: 2638-2640.

22. Grady WM, Carethers JM. Genomic and epigenetic instability in colorectal cancer pathogenesis. Gastroenterology. 2008;135: 1079-1099.

23. Carethers JM, Stoffel EM. Lynch syndrome and Lynch syndrome mimics: the growing complex landscape of hereditary colon cancer. World J Gastroenterol. 2015;21:9253-9261.

24. Koi M, Garcia M, Choi C, et al. Microsatellite alterations with allelic loss on 9p24.2 signify less-aggressive colorectal cancer metastasis. Gastroenterology. 2016. doi:10.1053/j.gastro.2015. 12.032 .

25. Tseng-Rogenski S, Chung H, Wilk MB, Zhang S, Iwaizumi M, Carethers JM. Oxidative stress induces nuclear-to-cytosol shift of hMSH3, a potential mechanism for EMAST in colorectal cancer cells. PLoS One. 2012;7:e50616.

26. Tseng-Rogenski S, Hamaya Y, Choi D, Carethers JM. Interleukin 6 alters localization of hMSH3, leading to DNA mismatch repair defects in colorectal cancer cells. Gastroenterology. 2015;148: 579-589.

27. Carethers JM, Koi M, Tseng-Rogenski S. EMAST is a form of microsatellite instability that is initiated by inflammation and modulates colorectal cancer progression. Genes. 2015;6:185-205.

28. Carethers JM. Racial and ethnic factors in the genetic pathogenesis of colorectal cancer. J Assoc Acad Minor Phys. 1999;10: $59-67$.

29. Carethers JM. Should African Americans be screened for colorectal cancer earlier? Nat Clin Pract Gastroenterol Hepatol. 2005;2:352-353.

30. Devaraj B, Lee A, Cabrera BL, et al. Relationship of EMAST and microsatellite instability among patients with rectal cancer. $J$ Gastrointest Surg. 2010;14:1521-1528.

31. Carethers JM, Murali B, Yang B, et al. Influence of race on microsatellite instability and $\mathrm{CD} 8^{+} \mathrm{T}$ cell infiltration in colon cancer. PLoS One. 2014;9:e100461.

32. Carethers JM. Screening for colorectal cancer in African Americans: determinants and rationale for an earlier age to commence screening. Dig Dis Sci. 2015;60:711-721.

33. Carethers JM, Braun J, Sands BE. Genetics, genetic testing and biomarkers of digestive diseases. Gastroenterology. 2015;149: 1131-1133.

34. Carethers JM, Jung BH. Genetics and genetic biomarkers in sporadic colorectal cancer. Gastroenterology. 2015;149:1177-1190. 